work under and with black doctors and I believe it gave me a unique opportunity to see something of their dilemma. I would like to draw your attention to some aspects of professional life which may be of interest to your readers.

That I was earning $£ 800$ a year more than my fellow African houseman indicates only a fraction of the total injustice. The fame of white South African medicine too often obscures the basic facts about the black South African scene. South Africa is one of the richest countries on the continent and yet I believe the level of poverty, malnutrition, ignorance, and social instability enforced on the majority of that country is incompatible with health.

The 1970 white infant mortality (rate per 1,000 live births) was 21.1.1 The Government will not publish African figures but a recent estimate ${ }^{2}$ has suggested an infant mortality rate as high as $400-450$ in some African areas. Diseases such as tuberculosis have a high incidence in South Africa. In 1966 the number of reported cases $/ 100,000$ African population was 446.5 and in 1968 was $469 \cdot 9 .{ }^{3}$ The degree of poverty may be gauged by comparison of wages with a recently estimated minimum effective (subsistence) level of R.100.69 a month for an African family of five. ${ }^{4} \mathrm{My}$ patients at King Edward's frequently had incomes as low as R.28 a month and rarely above R.64 a month. Official statistics show that in 1970 the average monthly cash earnings per head of African gold miners was R.17.7

The medical manpower and facilities available to black South Africa are stretched to their limits, and a political ideology which will not allow the different coloured groups to mix only aggravates the situation. Despite the imbalance of the doctor/patient ratios between the different coloured groups (approximately 1 per 455 white and 1 per 100,000 African population ${ }^{2}$ ) in 1970 several Indian doctors who were practising in grossly underdoctored African areas were prosecuted for occupying consulting rooms illegally in an African region (Group Areas Act).

The standard of medical education in the one black medical school (to which King Edward's is attached) was impressive, as were their graduates, but they are depressingly few. In 1970 , there were 3,918 white and 157 African medical students enrolled in South African universities. ${ }^{6}$ A main factor underlying the low output of black doctors is undoubtedly the low standard and high cost of pre-university African education. Though this group have the lowest incomes, the Africans are the only group who have to pay almost entirely for their own education.

Once qualified, the black postgraduate horizon is bleak. The academically barren "homelands" into which so many African doctors are being forced have virtually no facilities for specialist training. At King Edward's I found disillusionment among some of the senior black staff members as to whether they would ever be allowed to run their own medical school. Despite its 20year history, there are still no black professors and almost all the consultants are white, though at least two of the original group of students are now professors outside South Africa.

In our relative safety in Britain we should seriously consider what pressures we can bring to bear on South Africa to alleviate the suffering and injustices imposed on our colleagues, who for reasons of survival in hat police state may not speak out.

I find the policy of the B.M.A. and B.M.F. towards South Africa inconsistent. The fournal has carried a leader condemning "payment by colour" and yet it continues to carry frequent large advertisements for hospitals and universities which will take white applicants only at the stated white discriminatory salaries. By continuing to carry these advertisements, the British Medical fournal appears to be condoning medical prejudices based on colour and race.-I am, etc., Brook General Hospital,
London S.E.18

SUE Dowling

Republic of South Africa, House of Assembly Debates (Hansard) Minister of Statistics. 1971.
No. 18. Cols. 977-8. Cape Iown. Government Printer. 18

United Nations Unit on Apartheid. Inequality in Health Care in South Africa. New York, U.N. 3 Republic of South Africa. Department of Government Printing Offic South African Institute of Race Relations. Survey
of Race Relations in South Africa, 1971, 25, 178. Johannesburg. 1972. Department of Mines.
Republic of South Africa. Departh Statistics 1970. Cape Town.

Republic of South Africa. House of Assembly Debates (Hansard) Minister of National Educa-
tion. 1970, No. 2, cols. 539-40. Cape Town. Government Printer.

\section{Immune Suppression, Gliomas, and} Tuberculosis

SIR,-Dr. R. Finn and others (8 January, p. 111) refer to some clinical observations which seem to support the theory that neoplasia may partly be due to a deficiency in immunological surveillance. They suggest that in this respect the cellular immune system seems to be more important than the humoral antibodies. Pertaining to this view is the unifying concept of natural ageing and carcinogenesis in man. ${ }^{1}$ ' It assumes that, at least in part, somatic mutations may account for both processes. This concept emphasizes that an increase in the number of normal cells mutated into cancer cells will not necessarily lead to a corresponding increase in the incidence of cancer because the terrain must be propitious before a tumour can develop.

This theory could account for the increasing number of reports in which latent carcinoma has been found in the prostate, lung, kidney, and elsewhere. Little is known of the factors which influence the cellular immune system, but there is experimental evidence on the effect of calcium on the radiosensitivity at cellular level. From extensive studies a general hypothesis has evolved that chromosomes are inherently more sensitive to breakage at reduced levels of calcium. ${ }^{3}$ These observations could explain why patients with ankylosing spondylitis who had received $x$-ray treatment show an increased incidence of leukaemia. Owing to the calcium-depleted verebral bodies, $x$ radiation may lead to increased frequency of chromosome aberrations in the bone marrow, thus predisposing to the development of leukaemia. ${ }^{4}$

On the other hand, the observation of a negative calcified atherosclerosis-cancer relationship led to the concept that an ageing process in which the proteins and the lipoids have an increased affinity to calcium show a relative immunity to cancer, in particular to carcinoma of the stomach and colon, ${ }^{5}$ and may also be a factor in the latency and in the slow progression of some malignant tumours. ${ }^{6}$ - I am, etc.,

Prince of Wales General Hospital,
London N.15

A. Elkeles

Failla, G., Radiology, 1957, 69, 23.

Henshaw, P. S., Radiology, 1957, 69, 30

Elkeles, A., Nature, 1962, 193, 1089.

Elkeles, A., British Journal of Cancer, 1959, 13, 403. 572 .

\section{Menstrual Blood Loss and Fibrin} Degradation Products

SIR,-May I comment on the paper by Drs. Susan K. Cole and A. R. Clarkson on the relationship between menstrual blood loss and serum concentrations of fibrin degradation products ( 8 January, p. 78)? The authors were unable to confirm my findings (10 January, 1970, p. 74) of increased serum fibrin degradation products (F.D.P.) levels in women complaining of menorrhagia.

I wonder if the apparent lack of correlation between menorrhagia and high serum F.D.P. levels may be ascribed to differences in patients studied rather than to differences in laboratory methods as suggested by Drs. Cole and Clarkson. In the study reported by me, in all 70 women menorrhagia was the presenting symptom and the bleeding was severe enough to warrant gynaecological investigation as inpatients. Over half of these had haemoglobin values of less than $10.5 \mathrm{~g} / 100 \mathrm{ml}$. In my experience, collection of menstrual discharges by women attending hospital outpatients tends to be incomplete and creates a number of practical difficulties. It is well known that there is a wide variation of the normal range of menstrual blood loss. ${ }^{1}$ Thus an arbitrary upper limit of normal menstrual loss may not be valid for all women. It would seem reasonable and practicable to consider menstrual bleeding as excessive when the disability is severe enough for the woman to seek hospital treatment, and particularly when this is associated with diminished haemoglobin levels.

The criteria used for the definition of menorrhagia in the report by Drs. Cole and Clarkson are not clear. It is known that at least $40^{\circ} \prime$ of women with menstrual blood loss of $80 \mathrm{ml}$ or more per cycle do not complain of menorrhagia. ${ }^{1}$ Is it possible that the series reported by Drs. Cole and Clarkson has a preponderance of women with apparently normal menstrual loss? Of 331 women, 25 had losses in excess of $80 \mathrm{ml}$ and only 15 had losses in excess of $100 \mathrm{ml}$ per cycle. It may be of interest to ascertain how many of these women had complained of menorrhagia, were anaemic, or underwent gynaecological investigations. It is probable that a number of women considered to have menorrhagia by Drs. Cole and Clarkson would have been considered as having normal menstruation by standards employed in my study.

I am conscious of the dangers of drawing firm conclusions from the results of a single study. It is thus possible that the differences in serum F.D.P. levels observed between various groups of women reborted in my study were not due to variations in the degree of menstrual blood loss but to some other factors. Nevertheless, the results presented by Drs. Cole and Clarkion do not necessarily contradict my findings of 
increased serum F.D.P. levels in women with clinically significant menorrhagia, as compared with those in women without abnormal menstrual symptoms. Further studies being undertaken indicate that raised serum F.D.P. levels found in women with menorrhagia are often associated with increased levels of fibrin monomer complexes in the blood. Thus raised serum F.D.P. levels in women complaining of menorrhagia may be a manifestation of exaggerated intravascular microcoagulation associated with secondary fibrinolytic activity.-I am, etc.,

Liverpool Maternity Hospital,

H. K. BASU Liverpoo

1 Hallberg, L., Högdahl, A. M., Nilsson, L., and Scandinavica, 1966, 45, 320 .

\section{Serum Hepatitis Hazard in Biochemical} Control Sera

SIR,-We have found hepatitis associated antigen (H.A.A.) in two samples of com mercially produced human serum used a controls in biochemical tests. These are Hyland Q-Pak Chemistry Control Serum II batch no. 3655 M022A2 and Warner Chil cott Versatol Diagnostic Reagent batch no. 0089027. The antigen is present in high titre as shown by countercurrent electrophoresis, electron microscopy, and by ge diffusion. Identity can be shown in the las test with known positive antigens.

We have since tested several other batches of these manufacturers' products and 50 other samples of similar products with negative results.

In view of the obvious hazard to laboratory staff we strongly recommend that all such material should be tested for H.A.A. before use.-We are, etc.,

A. D. Evans

Public Health Laboratory

University Hospital of Wales.

KeIth Davies

\section{Antibiotic-resistant Gonococci}

SIR,-In your very useful leading article (18 December 1971, p. 696) you comment on the present halt in the increase of resistant gonococci in Britain and warn that this respite is likely to be only temporary. If this be so now is the time to take action to prevent a situation developing such as you describe in other parts of the world. But what action? We agree with your advice concerning treatment in the individual, but we think that more is needed. Unfortunately, however, the amount of useful advice which can be offered is limited by our ignorance.

We do not know enough about the two essential ingredients in the epidemic situation: the gonococcus and the population at risk. As to the gonococcus we could make a sizeable list of the relevant items which as yet are unknown, and as to the population it is now so heterogeneous and subject to rapid change that much we thought we knew is out of date. Clearly intensified bacteriological investigation and sociological study are called for. While awaiting these we would like to draw attention to the use of sensitivity testing not only to guide in the treatment of the individual and to monitor changes in the incidence of resistant strains but as a tool for epidemiological study. If the results of penicillin sensitivity tests are correlated, case by case, with information gained by clinician and social worker and the complete data analysed light is thrown on current epidemiological patterns and on the mechanisms of emerging resistance.

As an example of the value of such studies we refer you to our report ${ }^{1}$ on a study of penicillin-insensitive gonococci in the Bolton area in the months just prior to the introduction of high-dosage penicillin therapy in

1969. Among other observations we found a significant preponderance of insensitive strains in immigrants as compared with nonimmigrants, and also an apparent preponderance of insensitive strains in younger nonimmigrant females as compared with other indigenous groups. The latter finding we thought to be evidence that many young women were being treated elsewhere than in the clinic because, that being so, referrals would be mainly of those with resistant infections.

For analytical purposes we found that simple classification of strains by penicillin sensitivity was useful: sensitive (penicillin minimum inhibitory concentration $<0.015$ $\mu \mathrm{g} / \mathrm{ml}$ ); intermediate (M.I.C. $0.03-0.06$ $\mu \mathrm{g} / \mathrm{ml}$ ); and insensitive (M.I.C. $>0 \cdot 12 \mu \mathrm{g} /$ $\mathrm{ml}$ ). We encountered no highly insentitive strains but such a category would be desirable for strains of M.I.C. $>0.5 \mu \mathrm{g} / \mathrm{ml}$.

We provided evidence that penicillin M.I.C. is a sufficiently stable character of individual strains to be used epidemiologically in the way indicated. We believe that studies such as ours, on a greater scale, would provide results which would be very helpful in planning future control measures. -We are, etc.

P. S. Silver

Diagnostic Clinic, Health Department,

Bolton, Lancs

Silver, P. S., and Darling, W. M., British fourna

\section{Unusual Reaction to Trimethoprim} in Combined Therapy

SIR,-The use of a new drug, which associates a sulphonamide with trimethoprim, represents a therapeutic advance. This drug works on two consecutive levels of bacterial metabolism. and this diminishes the risk of acquired bacterial resistance. Soon after the drug came into use various side effects were reported, the most common being skin rashes.

I should like to report the following case in which a morbilliform rash appeared to be due to trimethoprim.

A 49-year-old woman had suffered from severe asthma since 1957. In February 1968 she had a thvroid nodule removed, and since then her asthma had been worse, with frequent attacks of status asthmaticus. Immunotherapy has been ineffective. She is also allergic to several drugs: aspirin, penicillin and aminopyrine and its derivatives.

On 22 January 1971 she became very dyspnoeic with wheezing and rhonchi, and had pus in the nose and sputum. She was put on sulfamethoxazole-trimethroprim: 400 $\mathrm{mg} / 80 \mathrm{mg}$ four times a day for 10 days. The therapeutic effect was good and pus disappeared both in nose and in sputum. On the tenth day a morbilliform rash appeared, localized to trunk and popliteal spaces, and she had joint pains. The administration of the drug was immediately stopped, and I prescribed $0.25 \mathrm{mg}$ betamethasone with $2 \mathrm{mg}$ dexchlorpheniramine in half dose three times a day for three days. The rash and arthralgias disappeared.

This observation resembles other reported cases, but, in this particular case, an interesting fact was mentioned by the patient. Two years before, she had an identical rash after having taken bamifylline (Trentadil) a bronchodilator which has in common with trimethoprim a pyrimidine nucleus.

Several weeks later the patient could take sulfamethoxazole without any reaction, and therefore I consider that in this case trimethoprim could be considered as responsible for the rash and arthralgia.

It seems that trimethoprim is seldom responsible for skin or systemic allergic reactions, but the possibility must be kept in mind when one prescribes the very useful combination of sulfamethoxazole-trimethoprim.-I am, etc., Paris

GEORgES M. HALPERN

\section{Rifampicin and Isoniazid and} Liver Function

SIR,-The experience of Dr. Satinder Lal and others (15 January, p. 148) on the effect of rifampicin and isoniazid (I.N.H.) on liver function is similar in a way to my own. I have found the rise of aspartate transaminase (SGOT) not to indicate significant abnormality of liver function and have naturally continued chemotherapy with rifampicin and isoniazid. I have, however, seen hepatotoxicity in patients receiving treatment for Mycobacterium tuberculosis infection with rifampicin and isoniazid when this is determined by measurement of bilirubin, alkaline phosphatase, and alanine transaminase (SGPT). The first indications have generally been symptomatic. Patients with these biochemical abnormalities, especially raised alanine transaminase, have generally felt unwell before biochemical detection of the abnormalities. The biochemical checks are carried out before and fortnightly after starting treatment.

A review of the experience of this clinic since 1969 showed that 26 patients had been treated with rifampicin and isoniazid up to early 1971. Of that number, eight (or $30 \%$ ) showed abnormality of liver function, indicated by raised bilirubin (more than $1 \mathrm{mg}$ / $100 \mathrm{ml}$ ), raised alkaline phosphatase (greater than $15 \mathrm{King}$ Armstrong units $/ 100 \mathrm{ml}$ ), and raised alanine transaminase (SGPT more than $40 \mathrm{~m}$. i.u. $/ \mathrm{ml}$ ). There was only one case of raised alkaline phosphatase alone. This was in a child of 6 years and the level was greater than 35 K.A. units. Treatment was continued without any adverse effect or any other abnormality. I have since been told that this is not unexpected in children and appears to be harmless. The alkaline phosphatase returned to normal values on cessation of therapy and the child has remained well thereafter. One case showed the bilirubin alone was raised. Here again treatment was continued and the values returned to normal eventually. There were no symptoms. In all the others there was abnormality of enzyme (SGPT) together with abnormality of either or both bilirubin and alkaline phosphatase. In these there were symptoms referrable to liver dysfunction such as anorexia, nausea, and vomiting. Also, 